\title{
A novel approach to the lumbar sympathetic chain: lateral access
}

\author{
Shaun D. Rodgers M.D., John A. Engler M.D., and Noel L. Perin M.D. \\ NYU Langone Medical Center, Department of Neurosurgery, New York, New York
}

\begin{abstract}
Plantar hyperhydrosis is a disabling condition of excessive, symmetric, focal sweating of the feet with social, psychological, and medical implications. Treatment options include topical agents, iontophoresis, botulinum toxin injection, and surgical disruption of the lumbar sympathetic chain.

Surgical corridors include transperitoneal and retroperitoneal approaches. We report our technique with a novel minimally invasive lateral retroperitoneal approach commonly used for lateral interbody fusions. The lateral approach for sectioning of the sympathetic chain in the treatment of hyperhydrosis appears safe. The approach may be advantageous for the patient and surgeons familiar with lateral interbody fusion. Further studies may elucidate the long term efficacy and safety of the lateral approach.

The video can be found here: http://youtu.be/Q82SGpmAXng.

(http://thejns.org/doi/abs/10.3171/2013.V2.FOCUS13204)
\end{abstract}

$\begin{array}{lllll}\text { KEY WoRDS } & \bullet \quad \text { lumbar } \bullet \quad \text { sympathectomy } \bullet \quad \text { plantar hyperhydrosis } \\ \text { lateral } \bullet \quad \text { video }\end{array}$

Manuscript submitted May 1, 2013.

Accepted June 11.

Please include this information when citing this paper: DOI: 10.3171/2013.V2.FOCUS13204.

Address correspondence to: Shaun Rodgers, M.D., New York University Langone Medical Center, Department of Neurosurgery, 462 First Avenue, Suite 7S4, New York, NY 10016. email: Shaun. Rodgers@nyumc.org. 